\title{
O problema do método dialético na correspondência de Walter Benjamin e Theodor Adorno durante a década de $1930^{1}$
}

\author{
Igor Lula Pinheiro Silva
}

Resumo: Este artigo tem como objetivo compreender o fundamento do debate teórico-metodológico estabelecido entre Walter Benjamin e Theodor Adorno acerca da dialética. Para tanto, realizamos análises críticas de alguns ensaios e cartas trocadas entre os autores durante a década de 1930. A tese sustentada neste artigo é a de que o referido debate implica um conflito entre as concepções de mediação e imediatez na análise dialética da sociedade.

Palavras-chave: Dialética; Crítica; Método; Mediação; Imediatez.

The problem of dialectical method in the correspondence between Walter Benjamin and Theodor Adorno in the 1930s

Abstract: The aim of this paper is to comprehend the foundation of the theoreticalmethodological debate between Walter Benjamin and Theodor Adorno about dialectics. To that end, critical analyses are made of some essays and letters exchanged by the authors in the 1930s. The thesis of this paper is that this debate implies a conflict between conceptions of mediation and immediacy in the dialectical analysis of society.

Keywords: Dialectics; Criticism; Method; Mediation; Immediacy.

El problema del método dialéctico en la correspondencia de Walter Benjamin y Theodor Adorno durante la década de 1930

Resumen: Este artículo tiene como objetivo comprender el fundamento del debate teórico-metodológico establecido entre Walter Benjamin y Theodor Adorno acerca de

\footnotetext{
${ }^{1}$ Recebido em 27/09/2016 e aprovado em 30/01/2017.

${ }^{2}$ Mestrando em Ciências Sociais pela Universidade Estadual Paulista (UNESP) e bolsista do Conselho Nacional de Desenvolvimento Científico e Tecnológico (CNPq). Contato: igorlulaps@gmail.com.
} 
$|110|$

O problema do método dialético...

la dialéctica. Para ello, realizamos análisis críticos de algunos ensayos y algunas cartas intercambiadas entre los autores durante la década de 1930. La tesis sustentada en este artículo es la de que este debate implica un conflicto entre las concepciones de mediación e inmediatez en el análisis dialéctico de la sociedad.

Palabras clave: Dialéctica; Crítica; Método; Mediación; Inmediatez.

\section{Introdução}

Walter Benjamin e Theodor Adorno, cada um à sua maneira, escreveram páginas importantes da história mais recente da dialética eisto não foi devido apenas ao fato de terem aparentemente formulado teses antagônicas sobre a condição social da arte em suas respectivas obras, mas também por terem estabelecido um diálogo bastante profícuo a respeito dos fundamentos da crítica dialética ao longo de seus contatos intelectuais. Benjamin e Adorno se conheceram em 1923 e, a partir deste ano até a morte de Benjamin, mantiveram uma interlocução que foi se tornando cada vez mais próxima e frequente: "Segundo relato do próprio Adorno, participavam juntos de seminários e, no mínimo uma vez por semana, encontravam-se com amigos para bate-papos intelectuais"; "Adorno escutava Benjamin com fascinação e este acabou por tornar-se o seu grande mestre" (KOTHE, 1978, p. 29). Entretanto, apesar das diversas convergências entre eles durante a década de 1920, esta relação ambivalente não poderia deixar de suscitar ocasiões nas quais se evidenciariam também divergências teóricas entre ambos, principalmente durante a década de 1930, no que diz respeito às análises estéticas e à própria crítica dialética. A seguir, discutiremos os fundamentos deste debate teóricometodológico.

Mapeamento do debate de Benjamin e Adorno acerca da dialética: algumas abordagens

O debate travado por Adorno e Benjamin acerca do problema da dialética foi documentado nas correspondências trocadas entre 
eles durante os anos 1930. A partir de 1934, como ressalta Nobre (1997, p. 45), a correspondência entre os dois intelectuais se tornou mais frequente e intensa devido, por um lado, às várias dificuldades proporcionadas pelo exílio imposto pela perseguição nazista e, por outro, ao debate crítico extremamente caloroso estabelecido entre ambos com relação aos textos que estavam sendo redigidos por eles próprios naquele período. Segundo Matos (2012, p. 15), estas correspondências são de importância inestimável para que se tornem compreensíveis os fundamentos de suas primeiras convergências e posteriores divergências teóricas cada vez mais acentuadas. Além disso, de acordo com as indicações de Gatti (2008, p. 15-16), devemos prestar a devida atenção ao fato de que estas mesmas correspondências apresentam uma flagrante mudança de tom: nas primeiras cartas, Adorno aparece na condição de um "jovem discípulo" que estuda com grande admiração e entusiasmo os textos escritos por Benjamin ao longo da década de 1920, em especial o ensaio As afinidades eletivas de Goethe (1922) e o livro Origem do drama barroco alemão (1928), buscando nestes textos as referências para seu próprio trabalho; enquanto que nas últimas cartas da década de 1930 a situação se inverte de forma peculiar, a ponto de Adorno exigir de Benjamin a reformulação de algumas teses apresentadas em seus textos posteriores, em especial no ensaio A obra de arte na era de sua reprodutibilidade técnica (1936) e no conjunto de textos sobre Charles Baudelaire, conhecido sob o título Charles Baudelaire: um lírico no auge do capitalismo (1938).

A relação entre os dois intelectuais se fortaleceu mais precisamente no ano de 1929, quando Benjamin teria apresentado a Adorno seus primeiros esboços do projeto das Passagens e, nesta ocasião, a possibilidade de uma espécie de cooperação intelectual entre os dois começava a se delinear com clareza. Nobre (1997, p. 46) defende a tese de que nesta ocasião estaria contida a origem de um "programa filosófico comum" para Benjamin e Adorno, o qual teria suas bases estabelecidas justamente pelo referido ensaio crítico sobre o romance de Goethe e pelo livro sobre o drama barroco de Benjamin. Neste período, como indica Gatti (2008, p.17), é possível notar com clareza que os pensamentos de Benjamin 
$|112|$

O problema do método dialético...

e de Adorno começaram a produzir grande influência recíproca, tendo em vista, por um lado, que Adorno passou a dar uma nova orientação a seus antigos trabalhos - como é o caso emblemático de sua tese de habilitação sobre Kierkegaard, defendida em 1930, mas publicada apenas em 1933, devido às diversas alterações do texto inspiradas pela influência do livro Origem do drama barroco alemão de Benjamin - e, por outro lado, também pelo fato de que Benjamin passou a reformular suas próprias concepções em um sentido mais materialista, em contraposição às formulações místicas e metafísicas identificadas por Adorno em seus escritos de juventude e nos primeiros esboços do projeto das Passagens. Nesta perspectiva, como observa Kothe, "reconhece-se cada vez mais a importância de Benjamin para a formação do pensamento adorniano", uma vez que "o texto de Adorno é, muitas vezes, especialmente quando se trata de literatura, um palimpsesto sob o qual podemos ler algum texto de Benjamin" (KOTHE, 1978, p. 17).

Não é desprovido de propósito ressaltar que, neste artigo, partimos da observação de que os textos de Adorno e Benjamin dialogam entre si. Entretanto, não apenas em termos de convergências, mas também de divergências, o que pode ser constatado a partir da análise minuciosa de suas correspondências. Como é possível observar, as primeiras divergências entre eles em relação à dialética surgiram precisamente na década de 1930. Em uma carta de 6 de novembro de 1934, Adorno afirma o seguinte:

Não pude reprimir as mais profundas reservas acerca de algumas de suas publicações (e isso pela primeira vez desde que nos aproximamos) [...]. Espero não ser suspeito de nenhuma interferência descabida se confesso que o pomo dessa discórdia toda está ligado à figura de Brecht e ao crédito que você lhe confere, e que isso toca também em questões fundamentais da dialética materialista [grifos nossos] (ADORNO \& BENJAMIN, 2012, p. 110111).

Este artigo procura construir uma constelação de elementos que mostre a existência de uma significativa divergência teórico- 
metodológica entre Adorno e Benjamin no que diz respeito à dialética. No caso específico desta carta, como explica Matos (2012, p. 32), do ponto de vista de Adorno, a aproximação de Benjamin e Brecht se apresentava como extremamente problemática, devido ao que parecia para Adorno uma influência de "marxismo vulgar", de "pensamento sem dialética" e de "crítica sem teoria" por parte de Brecht. Embora nossa proposta não seja esmiuçar as opiniões de Adorno sobre a relação entre Benjamin e Brecht, as observações de Adorno a este respeito são importantes para que se tornem compreensíveis os fundamentos da divergência entre ele e Benjamin no que se refere à dialética. Além da análise da influência de Brecht sobre Benjamin, outras duas vias de entrada já foram exploradas para a compreensão deste debate teórico-metodológico de Benjamin e Adorno, as quais tampouco serão integralmente percorridas ao longo deste artigo. De todo modo, é instrutivo mencioná-las aqui.

Por um lado, encontra-se a via de Matos (2012, p. 15), que sustenta a tese de que os fundamentos desta divergência teórico-metodológica devem ser compreendidos a partir da confrontação entre as progressivas conformações dos conceitos de "imagem dialética" e "dialética negativa" que se manifesta nas correspondências trocadas entre Benjamin e Adorno nos anos 1930. Para nós, está claro que, na década de 1920, Benjamin já havia produzido parte significativa de sua obra. A obra de Adorno, ao contrário, se comparada com a de Benjamin, se encontrava ainda muito incipiente no mesmo período e sua concepção de "dialética negativa" só se torna plenamente elaborada em 1966 com a publicação de sua obra homônima, após um longo período de confronto do pensamento adorniano com a filosofia de Hegel, um confronto que teria se intensificado justamente a partir da década de 1930. Apesar deste longo período de distância entre o livro Origem do drama barroco alemão (1928) de Benjamin e o livro Dialética negativa (1966) de Adorno, há um fio condutor que perpassa toda a obra de Adorno e de Benjamin, permitindo este tipo de interpretação, a saber: a relação entre mito e história. Entretanto, o intuito deste artigo não é confrontar as concepções de 
| 114 |

O problema do método dialético...

"imagem dialética" e "dialética negativa", pois consideramos esta abordagem excessivamente extemporânea e incapaz de revelar com clareza os fundamentos da divergência entre Benjamin e Adorno em relação à dialética, pois extrapola o recorte temporal da década de 1930 que encerra o debate teórico entre os autores.

Por outro lado, encontra-se a via aberta por Nobre (1997, p. 46) que defende a tese de que "só os escritos de Benjamin da década de 20 podem fornecer nitidez e consistência ao debate teórico que travam Adorno e o próprio Benjamin na década de 30", uma vez que Adorno insiste diversas vezes durante as correspondências que as soluções supostamente materialistas de Benjamin na década de 1930 se colocam aquém dos problemas propostos em seus textos da década anterior (mesmo que o próprio Adorno ainda não tivesse alcançado o êxito desejado na tarefa que cobrava de Benjamin naquela época). Entretanto, o intuito deste artigo tampouco é reconstruir em detalhes o referido "programa filosófico comum" estabelecido por Benjamin e Adorno no final da década de 1920, mas, sim, localizar e compreender os elementos fundamentais que, na década seguinte, viriam a colocá-lo em xeque devido ao dissenso entre ambos em relação à dialética.

Portanto, a via de entrada para a compreensão deste problema teórico-metodológico não são as opiniões de Adorno sobre a relação entre Benjamin e Brecht, nem a confrontação entre as conformações dos conceitos de "imagem dialética" e "dialética negativa" e tampouco a reconstrução do referido "programa filosófico comum" estabelecido por Benjamin e Adorno nos anos 1920. Em vez disso, a via percorrida aqui será a de explicitação de um conflito bastante específico entre as respectivas abordagens metodológicas dos autores, a saber: o conflito entre as concepções de mediação e imediatez na abordagem do objeto.

\section{Benjamin e a imediatez}

A imediatez acompanhou Benjamin desde seus escritos de juventude e estamos de acordo com Nobre (1997, p. 46) no que diz respeito à "clareza" e "consistência" que os mesmos fornecem ao 
posterior debate teórico-metodológico travado com Adorno. Já na década de 1910, no ensaio Sobre a linguagem em geral e a linguagem do homem (1916), em que a linguagem se apresenta como o Mediumda-comunicação, a imediatez desempenha um papel fundamental no método crítico de Benjamin, na medida em que proporciona uma síntese para a relação entre sujeito e objeto, implicando uma abordagem metodológica que compreende, por um lado, as condições imanentes de possibilidade da comunicação dentro dos limites da própria natureza da linguagem e, por outro, o potencial de produção infinita de variadas formas de expressão linguística. De acordo com o jovem filósofo:

\begin{abstract}
na linguagem é assim: a essência linguística das coisas é sua linguagem. A compreensão da teoria da linguagem depende da capacidade de levar essa asserção a um grau de clareza que elimine qualquer aparência de tautologia. Essa proposição não é tautológica, pois significa que aquilo que é comunicável em uma essência espiritual é sua linguagem. Tudo repousa nesse "é" (que equivale dizer "é imediatamente"). Não se trata de dizer que aquilo que em uma essência espiritual é comunicável se manifesta mais claramente na sua língua, $[\ldots]$ mas que esse elemento comunicável é a linguagem mesma sem mediações [grifo nosso] (BENJAMIN, 2013a, p. 53).
\end{abstract}

Neste texto, Benjamin (2013, p. 72) afirma que "a linguagem de um ser é o meio [Medium] em que sua essência espiritual se comunica". Em seus primeiros escritos, há uma concepção peculiar de linguagem com influências do pensamento mágico, metafísico e teológico da tradição judaica. Quando Benjamin afirma enfaticamente que é na linguagem - e não por meio [Mittel] dela - que as essências espirituais se comunicam, ele ressalta especificamente que esta comunicação ocorre de maneira imanente e imediata dentro dos limites e possibilidades da própria linguagem e nunca fora deles. Neste sentido, a linguagem não é entendida como o instrumento que cria um intermédio entre sujeito e objeto,

Idéias, Campinas, SP, v.8, n.1, p. 109-132, jan/jun. 2017 
$|116|$

O problema do método dialético...

tendo em vista a comunicação, mas a linguagem é o que unifica sujeito e objeto, criando as condições de possibilidade de qualquer comunicação entre ambos. Além disso, a imediatez do fenômeno linguístico caracteriza sua magia essencial e essa comunicação, que se realiza em diversas formas de expressão, percorre também toda a natureza, desde as coisas inanimadas, passando pelo ser humano, até alcançar Deus que, em termos míticos, se caracteriza como o ponto absoluto de todo o movimento da linguagem que se orienta em direção à infinitude da língua pura e do conhecimento perfeito. $\mathrm{Na}$ interpretação benjaminiana, o ser humano pode se comunicar com Deus a partir do conhecimento do nome verdadeiro das coisas, dos seres e dos eventos da natureza e a nomeação verdadeira das coisas é possível porque se realiza com base na comunicação que o ser humano recebe da natureza, uma vez que a natureza também é dotada de uma linguagem, lutuosamente muda e sem nome, que, após a Queda, corresponde ao resíduo da palavra criadora de Deus (BENJAMIN, 2013, p. 73).

Em sua tese de doutorado, $\mathrm{O}$ conceito de crítica de arte no romantismo alemão (1919), que também pode ser considerada como integrante do conjunto de textos benjaminianos de juventude, há um procedimento análogo em que a arte é compreendida como o Medium-da-reflexão. Benjamin observa a presença de uma imediatez na crítica de arte romântica, concebida como o registro histórico da autonomização da obra de arte singular em relação à religião e à tradição dogmática, implicando para sua abordagem metodológica, por um lado, uma análise estética imanente atenta à construção interna da obra de arte e, por outro, um procedimento crítico imanente que vincula reflexiva e sistematicamente a obra de arte particular à própria Ideia da arte que abarca a infinitude das formas-de-exposição (Darstellungsformen). Nas palavras de Benjamin:

Todo conhecimento crítico de uma conformação, enquanto reflexão nela [seria possível dizer imediatamente nela], não é outra coisa senão um grau de consciência mais elevado da mesma, gerado 


\begin{abstract}
espontaneamente. Esta intensificação da consciência na crítica é, a princípio, infinita; a crítica é, então, o medium no qual a limitação da obra singular liga-se metodicamente à infinitude da arte e, finalmente, é transportada para ela, pois a arte é, como já está claro, infinita enquanto medium-de-reflexão (BENJAMIN, 2002, p. 74).
\end{abstract}

Na filosofia estética do primeiro romantismo alemão, representada fundamentalmente pelas obras de Friedrich Schlegel e Novalis, Benjamin observa uma sistematicidade essencial proporcionada pela concepção de Medium, que permite aos leitores uma apreensão coordenada do conjunto aparentemente disperso de aforismos e fragmentos sobre arte dos primeiros românticos. Neste contexto, a concepção de Medium se apresenta propriamente como um recurso interpretativo para sistematizar a teoria estética do primeiro romantismo em função da exigência da crítica de arte. Na interpretação benjaminiana, a concepção de Medium se encontra diretamente associada ao conceito de reflexão de inspiração fichtena, caracterizando a arte especificamente como um Medium-da-reflexão. Assim, a crítica no pensamento dos primeiros românticos é interpretada por Benjamin como uma reflexão imediata, imanente e infinita na obra em relação ao Medium determinado como arte. Neste processo reflexivo, a especificidade da crítica é promover o movimento imediato de autoconhecimento e superação formal na própria obra, tendo em vista a apreensão da forma artística absoluta que é entendida como a Ideia da arte. Contudo, Benjamin assinala uma diferença fundamental entre as concepções de Fichte e as dos primeiros românticos:

Na reflexão, no entanto, existem, como se viu, dois momentos: a imediatez e a infinitude. A primeira fornece à filosofia de Fichte a indicação para buscar exatamente naquela imediatez a origem e a explicação do mundo; a segunda, no entanto, turva aquela imediatez, e deve ser eliminada da reflexão através de um processo filosófico. $\mathrm{O}$ interesse na imediatez 
$|118|$

O problema do método dialético...

do conhecimento mais elevado, Fichte compartilha com os primeiros românticos. O culto do infinito que eles fazem, como eles deixaram marcado também na teoria do conhecimento, separa-os dele e fornece ao pensamento deles o seu direcionamento mais original (BENJAMIN, 2002, p. 33).

Quando Benjamin afirma enfaticamente que é na obra de arte - e não por meio [Mittel] dela - que a crítica se realiza, ele ressalta especificamente a imanência e a imediatez necessárias do processo de reflexão da obra em relação ao absoluto da arte. Este absoluto da arte implica necessariamente uma infinitude do processo reflexivo desenvolvido pela crítica, pois a forma absoluta da arte nunca se realiza empiricamente, sendo possível apenas a apreensão cada vez mais sistemática do continuum das formas artísticas ao longo da história.

De todo modo, nestas interpretações da linguagem e do primeiro romantismo alemão, para o jovem Benjamin, imediatez significa uma determinada síntese de sujeito e objeto em que não há espaço para nenhum elemento intermediário ou exterior. Esta síntese torna o sujeito capaz, por um lado, de contemplar a verdade pela imanência do objeto e, por outro, compreender a vinculação do objeto ao absoluto ou à Ideia que corresponde em sua exposição ou apresentação (Darstellung).

No período materialista da obra de Benjamin, durante a década de1930, a imediatez permanece presente, mas adquire novos matizes e revela novos problemas epistemológicos na interlocução com Adorno, especialmente nos ensaios de teoria da arte e crítica literária ${ }^{3}$. No ensaio $A$ obra de arte na era de sua reprodutibilidade

\footnotetext{
${ }^{3}$ É preciso acrescentar que, tratando-se de Adorno e Benjamin, esta discussão a respeito da crítica dialética precisará ser devidamente vinculada tanto aos desdobramentos históricos da arte moderna quanto às próprias concepções estéticas postas no horizonte dos dois filósofos na primeira metade do século $\mathrm{XX}$, tendo em vista que ambos abordam as obras de arte de um ponto de vista social, levando em consideração suas transformações históricas de produção, reprodução, transmissão e recepção.
} 
técnica, Benjamin realiza um diagnóstico da modernidade e da condição social da arte a partir do desenvolvimento das novas técnicas de reprodução das obras de arte, as quais são representadas de maneira mais emblemática pela fotografia e pelo cinema. Quando Benjamin se debruça sobre a fotografia e o cinema, ele indica que existe uma profunda transformação social em curso nas sociedades capitalistas contemporâneas. Para compreender tais transformações, Benjamin se vale, dentre outros elementos, do conceito de aura que, segundo Palhares (2006, p. 107), consistiria justamente em uma de suas "imagens dialéticas". A concepção de aura sustentada por Benjamin, por um lado, procura captar de maneira crítica as transformações ocorridas nas relações sociais do mundo moderno e, por outro, procura evidenciar como as novas especificidades destas relações repercutem nas produções artísticas de um tempo histórico e de um espaço social regidos em quase sua totalidade pelo domínio técnico da vida e pela forma mercadoria. De acordo com Palhares (2006, p. 13-7), nos primeiros escritos de Benjamin a respeito da aura, verifica-se que o conceito estava situado, em grande medida, no âmbito do debate teológico, cujo foco era especialmente a temática do misticismo judaico. Isto implica diversas tensões e controvérsias a respeito da posterior discussão do declínio da aura das obras de arte tradicionais na obra benjaminiana, pois, principalmente ao longo da década de 1930, a interpretação que Benjamin faz deste declínio é extremamente ambivalente, em alguns momentos apreciando-o e, em outros, lamentando-o; e apenas no final desta década o problema da perda da aura se relaciona consistentemente com outros temas importantes de sua obra como, por exemplo, a crise da experiência e da narração.

Neste sentido, existe um evidente descompasso entre as teses apresentadas nos textos de juventude e nos textos de maturidade de Benjamin. Um aspecto relevante para a compreensão do problema do conceito de aura é justamente o fato de que a década de 1930 marca o momento de adoção de uma perspectiva materialista por parte do pensamento benjaminiano. Na década de 1930, sob 
| 120 |

O problema do método dialético..

influências marxistas de Lukács, Brechte Adorno, Benjamin começa a concentrar suas reflexões nas condições sociais de produção, reprodução, transmissão e recepção das obras de arte no contexto da sociedade industrial moderna. Isto implica uma mudança de foco em sua análise a respeito do tema da aura, transitando do debate teológico para um campo de discussão materialista, baseado em larga medida no marxismo, cuja especificidade passa a residir na tentativa de apreensão das transformações ocorridas historicamente na base material das obras de arte tradicionais, a partir da descoberta de novas técnicas de produção e reprodução e também das modificações ocorridas nas formas de transmissão e recepção das obras pelo público mediante os avanços técnicos dos próprios meios de produção da sociedade capitalista moderna. Portanto, a noção de obra de arte aurática e, sobretudo, a percepção da perda da aura das obras de arte tradicionais permitem que Benjamin explique, a partir da perspectiva materialista com traços teológicos que lhe é própria, um processo que diz respeito ao desenvolvimento geral das sociedades modernas. Segundo a avaliação de Gagnebin $(1987$, p. 8):

\begin{abstract}
Alguns fazem de Benjamin um materialista otimista, que celebraria o fim da arte tradicional em proveito da união entre arte e técnica (a partir da interpretação do ensaio $A$ obra de arte na época de sua reprodutibilidade técnica); outros, particularmente Adorno e seus discípulos, consideram-no um observador de gênio mas um dialético medíocre, incapaz de uma verdadeira reflexão teórica; outros, enfim, vêem-no um teólogo e um místico judeu, perdido nos caminhos do marxismo $[\ldots]$.
\end{abstract}

\title{
A crítica de Adorno a partir da concepção de mediação
}

É interessante levar em consideração uma carta de 18 de março de 1936, na qual Adorno expõe algumas de suas impressões 
e ressalvas a respeito do trato dialético das questões estéticas realizado por Benjamin em seu ensaio $A$ obra de arte na era de sua reprodutibilidade técnica. No início da carta lê-se o seguinte:

\begin{abstract}
Não há uma única frase [de seu ensaio] que eu não gostaria de discutir com você em pormenores. [...] Expresso meu passional interesse e estou de pleno acordo no tocante àquele aspecto em sua obra que me parece o cumprimento de suas intenções originais - a construção dialética da relação entre mito e história - no domínio da dialética materialista: a autodissolução dialética do mito, que é visada aqui como desencantamento da arte. Você sabe que a questão da "liquidação da arte" está há muitos anos por trás dos meus ensaios estéticos e que a ênfase com que defendo o primado da tecnologia, sobretudo na música, deve ser entendida estritamente nesse sentido e no sentido de sua segunda peça sobre técnica. Não me admira que tenhamos aqui uma base comum; não me admira, visto que seu livro sobre o barroco traçou a distinção entre alegoria e símbolo ("aurático", em sua terminologia), e a Rua de mão única, entre obra de arte e documentação mágica [...]. E uma tal consonância é também o que constitui para mim o critério das diferenças que sou obrigado a constatar, com o único objetivo de servir àquela nossa "linha geral" que agora se esboça com tanta clareza (ADORNO \& BENJAMIN, 2012, p. 206-207).
\end{abstract}

O início desta carta de Adorno a Benjamin sintetiza e dá destaque a alguns dos elementos mencionados anteriormente, uma vez que o próprio Adorno reconhece suas simultâneas convergências e divergências teóricas com Benjamin. Por um lado, Adorno ressalta os diversos temas em comum entre seus textos como, por exemplo, o primado da tecnologia nas questões estéticas, a relação entre mito e história e a autodissolução dialética do mito - e ainda alude àquela linha geral, estabelecida especialmente 
$|122|$

O problema do método dialético...

pelo livro de Benjamin sobre o drama barroco, através da qual ambos orientariam seus respectivos trabalhos por alguns anos. Por outro lado, em nome de tal consonância, Adorno se vê, ao mesmo tempo, obrigado a realizar as devidas ressalvas com relação à abordagem dialética dos temas tratados por Benjamin em seu ensaio, evidenciando, portanto, suas simultâneas divergências. Mais adiante, na mesma carta, Adorno afirma o seguinte:

Em seus escritos anteriores, de que o presente ensaio me parece ser continuação, você distinguiu o conceito de obra de arte como estrutura tanto do símbolo da teologia como do tabu mágico. Mas agora me causa certa inquietação, e nisso enxergo um resquício sublimado de certos temas brechtianos, que você tenha transferido a esmo o conceito de aura mágica à "obra de arte autônoma" e atribuído categoricamente a esta uma função contrarrevolucionária. Não preciso lhe certificar de que tenho plena consciência do elemento mágico presente na obra de arte burguesa (quando mais não seja porque sempre procuro revelar a filosofia burguesa do idealismo, que está associada ao conceito de autonomia estética, como mítica em pleno sentido). Parece-me porém que o cerne da obra de arte autônoma não integra a dimensão mítica - perdoeme o linguajar tópico -, mas antes é intrinsecamente dialético, ou seja, em seu interior mesclam-se o mágico e o signo da liberdade. [...] Entenda bem: não quero assegurar a autonomia da obra de arte como prerrogativa, e concordo com você em que o elemento aurático da obra de arte está em declínio [...]. Mas a autonomia da obra de arte - a sua forma material, portanto - não é idêntica ao elemento mágico que ela encerra [...] Você subestima a tecnicidade da arte autônoma e superestima a da dependente; em suma, essa seria talvez minha principal objeção (ADORNO \& BENJAMIN, 2012, p. 206-212). 
Em síntese, o que Adorno exige de Benjamin é "mais dialética" (ADORNO \& BENJAMIN, 2012, p. 212). Em seu ensaio sobre a obra de arte, Benjamin (2012, p. 179-180) afirma que os novos mecanismos de reprodução técnica seriam responsáveis por promover a derrocada da arte tradicional burguesa, que seria baseada estritamente nas noções de unicidade e autenticidade da obra de arte (os fundamentos da existência da aura). Para Benjamin, este processo implicaria, por um lado, o surgimento de uma arte não aurática com o potencial revolucionário de contribuir para a consciência de classe do proletariado e, por outro, a possibilidade de existência de uma estética impossível de ser apropriada pela política do fascismo. Entretanto, como afirma Kothe (1978, p. 43): "Adorno mostra-se contra a transposição direta da aura mágica à obra de arte autônoma, processo em que esta aparece como antirrevolucionária; e aí combate tendências 'brechtianas' de Benjamin". Neste sentido, sob a perspectiva de Adorno, o texto de Benjamin não seria realmente dialético, pois não leva devidamente em conta a dinâmica imanente da obra de arte autônoma no que diz respeito à sua tensão necessária entre o elemento mágico e o signo da liberdade. Na mesma carta, Adorno ainda afirma enfaticamente que:

Les extrèmes me touchent, tanto quanto a você: mas somente se a dialética do mais baixo for equivalente à do mais alto, e não se esse último for abandonado à própria ruína. Ambos carregam os estigmas do capitalismo, ambos contêm elementos de mudança [...]; ambos são metades dilaceradas da liberdade integral, que no entanto não é igual à soma das duas (ADORNO \& BENJAMIN, 2012, p. 210).

E, mais adiante, Adorno acrescenta categoricamente "que ela [a principal objeção de Adorno] seja entendida como uma dialética entre os extremos, que você [Benjamin] rasga em dois" (ADORNO \& BENJAMIN, 2012, p. 212). Estas afirmações certamente revelam a origem da principal objeção de Adorno em relação aos textos de Benjamin, a saber: a falta de mediação dialética. 
$|124|$

O problema do método dialético...

No entanto, apesar do reconhecimento da importância das críticas de Adorno, a resposta de Benjamin é lacônica, hesitando prosseguir o debate teórico por meio das cartas e privilegiando uma discussão face a face:

terei de adiar um exame mais detido de sua longa carta acerca do trabalho sobre a teoria da arte, e de preferência adiá-lo um pouco mais - isto é, até nosso encontro (assim espero) iminente. Seja como for, não consigo mais imaginar meus próprios apontamentos sem referência a essa carta. Suas posições me são claras mesmo quando entram em confronto com as minhas. Todos os detalhes terão de ser referidos com extrema cautela. Foi-me absolutamente esclarecedora sua alusão a Mallarmé, em cuja obra, de fato, cabe tornar presente (se tanto) sobretudo um aspecto da arte livre ritual e puramente dialético (ADORNO \& BENJAMIN, 2012, p. 222).

Apenas dois anos mais tarde, em um ensaio intitulado O fetichismo na música e a regressão da audição (1938) que "foi escrito, segundo declaração do próprio Adorno, como resposta ao ensaio de Benjamin sobre 'A obra de arte'"', Adorno procurou demonstrar de que maneira alguns dos elementos observados por Benjamin nas transformações históricas de produção, reprodução, transmissão e recepção das obras de arte têm um impacto nocivo sobre a produção cultural contemporânea (KOTHE, 1978, p. 47). Em resposta a Benjamin, Adorno (1996, p. 66-77) afirma que as técnicas de reprodução da obra de arte, associadas à lógica do mercado, são responsáveis, por um lado, por converter o antigo público ativo em meros consumidores passivos e, por outro lado, por promover uma regressão da cognição e das formas de sensibilidade dos indivíduos, provocando o declínio da subjetividade autônoma e da fruição intelectualmente ativa da obra de arte. Neste sentido, sob a perspectiva de Adorno, as novas transformações históricas no campo estético, observadas por Benjamin com tanto entusiasmo, não apresentariam necessariamente algo de progressista, revolu- 
cionário ou emancipatório. De acordo com Gagnebin (1987, p. 56), Adorno

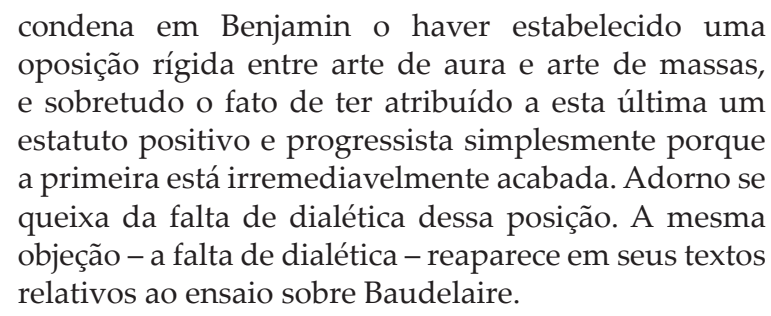
oposição rígida entre arte de aura e arte de massas, e sobretudo o fato de ter atribuído a esta última um estatuto positivo e progressista simplesmente porque a primeira está irremediavelmente acabada. Adorno se queixa da falta de dialética dessa posição. A mesma objeção - a falta de dialética - reaparece em seus textos relativos ao ensaio sobre Baudelaire.

Todas as objeções de Adorno ao procedimento metodológico de Benjamin parecem gravitar em torno de um problema bastante específico: a falta de mediação dialética na abordagem do objeto. Nas últimas correspondências trocadas entre eles, no final da década de 1930, cujo tema central consiste nos textos sobre Baudelaire, a querela acerca da dialética adquire maior tensão, curiosamente, ao mesmo tempo em que as referências à base comum para os dois filósofos, estabelecida ao longo dos anos de 1920, se tornam mais frequentes. Em uma carta de 10 de novembro de 1938, em diversos momentos, Adorno procura ressaltar que suas observações e, mais precisamente, suas divergências teóricas em relação a Benjamin a respeito do trato dialético da obra de Baudelaire estão orientadas justamente por aquelas convergências da década anterior. Nesta carta, é possível notar que aparecem de maneira flagrante, por um lado, a convergência expressa na exaltação de fidelidade ao projeto comum da década anterior e, por outro, a divergência com relação ao problema da imediatez na abordagem benjaminiana do objeto. Especialmente no trecho a seguir, as declarações de Adorno são muito claras no que diz respeito às suas divergências metodológicas com Benjamin:

Vejo um vínculo estreito entre as partes nas quais o próprio a priori do texto perde terreno e a sua relação com o materialismo dialético [...]. Permita-me aqui me expressar de modo tão simples e hegeliano possível. 
$|126|$

O problema do método dialético...

Ou muito me engano ou essa dialética é falha numa coisa: em mediação. Reina soberana uma tendência de relacionar os conteúdos pragmáticos de Baudelaire diretamente aos traços contíguos da história social do seu tempo, e tanto quanto possível aos de natureza econômica. [...] tento indicar o fundamento teórico de minha aversão a esse particular tipo de concretude e seus laivos behavioristas. Outra não é a razão disso senão que reputo metodologicamente infeliz dar emprego "materialista" a patentes traços individuais da esfera da superestrutura ligando-os de maneira imediata, e talvez até causal, a traços análogos da infraestrutura. A determinação materialista de caracteres culturais só é possível se mediada pelo processo total [grifo no original]. [...] O trabalho das Passagens [grifo do original], em sua forma definitiva, não poderá eximir-se dessa obrigação. [...] Esse tipo de materialismo imediato - eu já ia quase dizendo esse tipo de materialismo antropológico - embute um elemento profundamente romântico, e sinto-o com tanto mais clareza quanto mais abrupto e cru é seu confronto entre o mundo baudelairiano das formas e as necessidades da vida. A "mediação" de que sinto falta e julgo encoberta pela evocação materialistahistoriográfica não é outra coisa senão a própria teoria de que seu trabalho se abstém. [...] Dito de outro modo: o tema teológico de chamar as coisas pelo nome tende a se tornar uma apresentação estupefata de meras facticidades. Se se pudesse falar em termos drásticos, poder-se-ia dizer que seu trabalho situa-se na encruzilhada de magia e positivismo. [...] Sua solidariedade com o Instituto, com a qual ninguém se alegra mais do que eu próprio, induziu-o a pagar ao marxismo tributos que não fazem jus nem a ele nem a você (ADORNO \& BENJAMIN, 2012, p. 398-404, grifos nossos, exceto onde indica-se o contrário).

Nesta carta de Adorno, é possível perceber com clareza mais dois elementos mencionados anteriormente: por um lado, a 
mudança de tom por parte de Adorno em relação às primeiras cartas trocadas com Benjamin e, por outro, as acusações de "marxismo vulgar", "pensamento sem dialética" e "crítica sem teoria" nas análises estéticas realizadas por Benjamin durante a década de 1930 (MATOS, 2012, p. 32). Como indica Gagnebin (1987, p. 57): "Adorno chega a dizer que Benjamin talvez se utilize das categorias materialistas, mas que esse materialismo está mais próximo de um positivismo descritivo do que de uma análise dialética". A argumentação realizada por Adorno para sustentar estas críticas à falta de mediação dialética nos textos de Benjamin é coerente, de acordo com a própria carta, com a tradição dialética hegeliana, bem como com a postura assumidamente marxista do Instituto para a Pesquisa Social de Frankfurt. O prefácio à Fenomenologia do espirito (1807) é um dos mais conhecidos momentos em que Hegel destaca a necessidade da mediação para a compreensão dialética do devir do todo:

O verdadeiro é o todo. Mas o todo é somente essência que se implementa através de seu desenvolvimento. Sobre o absoluto, deve-se dizer que é essencialmente resultado; que só no fim é o que é na verdade. Sua natureza consiste justo nisso: em ser algo efetivo, em ser sujeito ou vir-a-ser-de-si-mesmo. Embora pareça contraditório conceber o absoluto essencialmente como resultado, um pouco de reflexão basta para dissipar esse semblante de contradição. O começo, o princípio ou o absoluto - como de início se enuncia imediatamente - são apenas o universal. Se digo: "todos os animais", essas palavras não podem valer por uma zoologia. Do mesmo modo, as palavras "divino", "absoluto", "eterno" etc. não exprimem o que nelas contém; - de fato, tais palavras só exprimem a intuição como algo imediato. A passagem - que é mais que uma palavra dessas - contém um tornar-se Outro que deve ser retomado, e é uma mediação; mesmo que seja apenas passagem a outra proposição. Mas o que horroriza é essa mediação: como se fazer uso dela fosse 
$|128|$

O problema do método dialético...

abandonar o conhecimento absoluto - a não ser para dizer que a mediação não é nada de absoluto e que não tem lugar no absoluto (HEGEL, 2014, p. 33-34).

Mesmo que Adorno afirme posteriormente a falsidade do todo, a concepção de movimento dialético presente nesta passagem de Hegel ainda pode ser considerada uma referência significativa para a compreensão da crítica de Adorno à imediatez benjaminiana. Em Hegel, a totalidade aponta para o momento de superação do dado imediato em um movimento de salto para além de si mesmo. Nas palavras de Safatle (2013, p. 26), a totalidade hegeliana "não deve ser compreendida como determinação normativa capaz de definir, por si só, o sentido daquilo que ela subsume, mas como a força de descentramento da identidade autárquica dos particulares". Assim, a mediação é a responsável pelo movimento de totalização dos conteúdos particulares da experiência, tornando-a acessível ao saber da consciência e criando para ela uma sucessão, sem que o conteúdo seguinte seja uma simples anulação do anterior, pois trata-se de um movimento que revela cada um dos momentos particulares da experiência como limitados, parciais e profundamente interdependentes uns dos outros. Neste sentido, a totalidade não é a negação simples do particular, mas o resultado, por um lado, da compreensão da particularidade e limitação do dado imediato e, por outro, da necessidade de que este dado imediato seja sempre mais do que si-mesmo. Contudo, esta sucessão de um momento a outro da experiência não se apresenta como uma passagem contínua, mas como ruptura e dissolução de extremos. Em Hegel, a totalidade é uma processualidade que cria relações necessárias entre conteúdos particulares experimentados de maneira imediata, sendo a mediação, por sua vez, não um mero termo intermediário entre extremos, mas a compreensão de sua vinculação necessária, bem como a sua posterior superação, que se realizam no movimento contínuo de formação do todo.

O dissenso teórico-metodológico entre Adorno e Benjamin a este respeito foi se tornando cada vez mais evidente, a ponto de 
Adorno (1998, p. 232) observar, muitos anos mais tarde, em um de seus ensaios da década de 1950, intitulado Caracterização de Walter Benjamin (1955), que "a concepção de mediação universal, que tanto em Hegel quanto em Marx funda a totalidade, nunca foi plenamente apropriada por seu método microscópico e fragmentário". Entretanto, suspeitamos que a dialética no pensamento de Benjamin, deliberadamente renuncia ou, pelo menos, prescinde da mediação com o processo total, tal como exigia Adorno na década de 1930, apontando para uma tensão imediatamente perceptível na imanência do objeto. Como o próprio Adorno (1998, p. 232) observa precisamente em seu ensaio sobre Benjamin da década de 1950: "para ele [Benjamin], interpretar fenômenos de modo materialista significava menos explicá-los a partir da totalidade social do que relacioná-los imediatamente [grifo nosso], em sua individuação, a tendências materiais e lutas sociais".

\section{À guisa de conclusão}

O fundamento do debate teórico-metodológico travado por Theodor Adorno e Walter Benjamin acerca da dialética se encontra no conflito entre as concepções de mediação e imediatez na abordagem do objeto. Tal imediatez pode ser encontrada na obra de Benjamin desde os seus primeiros escritos da década de 1910, especialmente naqueles que versam sobre arte e linguagem - influenciados principalmente pelo pensamento judaico e pelo romantismo alemão. Contudo, no período de influência marxista da década de 1930 em que Benjamin se compromete em termos teóricometodológicos com a dialética materialista, Adorno observa uma incompatibilidade epistemológica entre, por um lado, a imediatez permeada pelas influências judaica e romântica do jovem Benjamin e, por outro, a exigência de uma análise dialética e materialista de matriz hegeliana e marxiana. Ainda assim, é importante perceber que não se trata de simplesmente eliminar dos ensaios críticos de Benjamin a presença dos momentos de imediatez. De acordo com Adorno, a questão problemática é a permanência autárquica de tais momentos, os quais carecem de um movimento de mediação 
| 130 |

O problema do método dialético..

que torne o processo total compreensível em termos teóricos que privilegiam uma abordagem materialista e historiográfica. Dentro deste recorte da década de 1930, Adorno enfatiza que a ausência de mediação do objeto particular com o processo total nos ensaios críticos de Benjamin somente descaracteriza o pensamento dialético fundamentado na tradição inaugurada por Hegel e, portanto, parece tornar inconcebível a possibilidade de uma dialética imediata ou mesmo com ênfase nos momentos de imediatez.

Em uma das últimas cartas enviadas a Adorno, em 9 de dezembro de 1938, em uma tentativa de conciliação, Benjamin procura responder às objeções de Adorno em relação aos seus textos. Nesta carta, Benjamin afirma que não é capaz de dizer seguramente se as diferenças de abordagem entre eles são necessariamente condicionadas por divergências teóricas (ADORNO \& BENJAMIN, 2012, p. 419). Para Benjamin, que buscava de alguma forma conciliar suas posições com as de Adorno, talvez se tratassem apenas de "diferenças aparentes entre duas perspectivas que na verdade, igualmente adequadas, incidem sobre objetos diversos" - em um caso sobre a percepção ótica e, em outro, sobre a percepção acústica (ADORNO \& BENJAMIN, 2012, p. 419). Segundo Benjamin, uma análise do filme sonoro e de seus impactos sociais possivelmente forneceria uma crítica de arte contemporânea que seria capaz de mediar, no sentido dialético tanto exigido por Adorno, as duas visões aparentemente divergentes (ADORNO \& BENJAMIN, 2012, p. 420). Esta análise sugerida por Benjamin é, em grande medida, desenvolvida por Adorno no ensaio sobre a indústria cultural da Dialética do esclarecimento (1947). No entanto, isto ocorre justamente no momento em que o debate entre os dois filósofos é irremediavelmente interrompido, devido à morte de Benjamin, em 1940. 


\section{Referências}

ADORNO, T. W. O fetichismo na música e a regressão da audição. In: Theodor W. Adorno: textos escolhidos. Trad. Luiz João Baraúna. São Paulo: Nova Cultural, 1996, p. 65-108.

Caracterização de Walter Benjamin. In: Prismas: crítica cultural e sociedade. Trad. Flávio René Kothe. São Paulo: Ática, 1998, p. 223-237.

ADORNO, T. W.; BENJAMIN, W. Correspondência: 1928-1940. Trad. José Marcos Mariani de Macedo. São Paulo: Editora UNESP, 2012.

BENJAMIN, W. O conceito de crítica de arte no romantismo alemão. Trad. Márcio Seligmann-Silva. São Paulo: Iluminuras, 2002.

A obra de arte na era de sua reprodutibilidade técnica. In: Obras escolhidas I: magia e técnica, arte e política. Trad. Sérgio Paulo Rouanet. São Paulo: Brasiliense, 2012, p. 179-212.

. Sobre a linguagem em geral e a linguagem do homem. In: Escritos sobre mito e linguagem (1915-1921). Trad. Susana Kampff Lages. São Paulo: Duas Cidades; 34, 2013, p. 49-73.

GAGNEBIN, J. M. Walter Benjamin: os cacos da história. São Paulo: Brasiliense, 1987.

GATTI, L. F. O foco da crítica: arte e verdade na correspondência entre Adorno e Benjamin. Campinas: [s. n.], 2008.

HEGEL, G. W. F. Fenomenologia do espírito. Trad. Paulo Meneses. Petrópolis: Vozes; Bragança Paulista: Editora Universitária São Francisco, 2014.

KOTHE, F. R. Benjamin e Adorno: confrontos. São Paulo: Ática, 1978.

MATOS, O. C. F. Walter Benjamin e Theodor Adorno: o estupor da facticidade à meia-noite do século. In: ADORNO, T. W.; 
$|132|$

O problema do método dialético...

BENJAMIN, W. Correspondência: 1928-1940. São Paulo: Editora UNESP, 2012, p. 15-46.

NOBRE, M. Objeções marxistas? Adorno e Benjamin na "encruzilhada de magia e positivismo" dos anos 30, Cadernos de filosofia alemã, n. 3, p. 45-59, 1997.

PALHARES, T. H. P. Aura: a crise da arte em Walter Benjamin. São Paulo: Barracuda, 2006.

SAFATLE, V. Os deslocamentos da dialética. In: ADORNO. T. W. Três estudos sobre Hegel. São Paulo: Editora UNESP, 2013, p. 11-61. 